\title{
Ampliando as Ações Educativas dos Museus por meio da Formação de Comunidades Virtuais de Aprendizagem
}

Ana Carolina Bertoletti De Marchi Antônio Carlos da Rocha Costa

\section{Enhancing Educational Actions in Museums Through Virtual Learning Communities}


Resumo: Este artigo tem como objetivo mostrar que é possível incentivar a aprendizagem informal em museus através da construção de comunidades virtuais, com base em repositórios de objetos de aprendizagem, ferramentas comunicacionais e produção de OAs por parte dos visitantes. O enfoque é incentivar a aprendizagem no sentido de motivar a participação/envolvimento do visitante nas atividades da comunidade virtual. Nesta perspectiva, partimos do pressuposto de que a informação, a comunicação, a interação e a cooperação são essenciais para o processo de aprender no contexto informal dos museus. Acreditamos que a interação e a cooperação são partes integrantes do processo de aprendizagem proporcionado por comunidades virtuais e que o principal recurso de aprendizagem oferecido nessas comunidades são os objetos de aprendizagem. Diante do exposto, construímos a Comunidade Virtual do Muzar e realizamos uma experimentação do ambiente de modo a verificar o quanto os visitantes são incentivados a produzir novos conhecimentos.

Palavras-Chave: Comunidades Virtuais de Aprendizagem. Aprendizagem Informal em Museus. Informática na Educação em Museus. Objetos de Aprendizagem.

Abstract: The goal of this paper is to show that it is possible to stimulate informal learning in museums by means of virtual communities based on repositories of learning objects, communicatory tools and the production of learning objects by the visitors. The focus of the work is to stimulate informal learning by motivating the participation/involvement of the visitor in the activities of a virtual community of museum's visitors, following the assumption that information, communication, interaction and cooperation are essential for the learning process in the informal context of museums. We believe that the informal learning process that can be provided by virtual communities, together with learning resources like learning objects, can provide the necessary means for the educational actions in museums. In view of this, we have built and successfully experimented with CV-Muzar, a learning object-based virtual community environment for the Augusto Ruschi Zoobotanic Museum at UPF, that we report in this paper.

Keywords: Virtual Communities. Informal Learning. Computer Science in the Education in Museums. Learning Objects.

MARCHI, Ana Carolina Bertoletti de; COSTA, Antônio Carlos da Rocha. Ampliando as Ações Educativas dos Museus por meio da Formação de Comunidades Virtuais de Aprendizagem. Informática na Educação: teoria \& prática, Porto Alegre, v.9, n.1, p.83-96, jan./jun. 2006. 


\section{Introdução}

Ao longo dos tempos a definição de museu mudou muito. Atualmente, é reconhecido que sua função não se limita ao ato de coletar, restaurar e expor objetos que compreendem o acervo. A pesquisa, a divulgação e a socialização do conhecimento tornaram-se elementos determinantes nas funções sociais dos museus. Cada vez mais, o objetivo dos museus é ajudar as pessoas a compreenderem o mundo que as cerca, visando a atingir, desse modo, tanto a população em geral como, especialmente, crianças e jovens em idade escolar e, por conseqüência, professores que com eles atuam.

Os museus são excelentes espaços para construir conhecimento, despertando a investigação e desenvolvendo a capacidade de solucionar problemas. Vê-se que o papel educacional dos museus é muito amplo e realmente é esta a sua missão principal. Os museus têm condições de desempenhar uma importante função para o crescimento do nível educacional da população, completando a aprendizagem tanto dos alunos que ainda freqüentam as escolas como do público em geral. A atuação constante dos museus junto às escolas oferece novas opções para o trabalho didático, não só no espaço fechado das salas de aulas, mas também utilizando o meio físico e humano (SANTOS, 1987).

Adicionalmente, apoiados pelo avanço da tecnologia, os museus podem fornecer uma grande gama de educação interativa por meio dos seus experimentos. Tais experimentos instigam o visitante a investigar usando ferramentas científicas e instrumentos que podem encorajá-lo a observar, a procurar relações e a tirar suas próprias conclusões.

Esses ambientes educacionais dis- põem, independentemente de sua eficácia, de inúmeras estratégias comunicativas para explicitar o conteúdo das exposições, utilizando diferentes linguagens com o objetivo de torná-lo percebível e de ser interpretado pelo visitante. A internet é o mais novo meio de comunicação que vem despontando no mundo museal, por oportunizar diferentes estratégias comunicativas. Quando a comunicação se estabelece com o objetivo de fazer o visitante conhecer uma informação, podemos dizer que existe a intenção de ensinar (BLANCO, 1997, p.85).

Neste artigo, partimos do pressuposto de que, com a mudança do conceito dos museus, abriram-se novas oportunidades, permitindo a incorporação da linguagem interativa nas exposições para aprimorar a aprendizagem informal. Nesse processo, a formação de comunidades virtuais de aprendizagem assume um papel importante para ampliar as ações educativas dentro e fora dos museus. Assim, apresentaremos um pouco das ações educativas dos museus e como as comunidades virtuais de aprendizagem podem potencializar esse processo. Também descreveremos a Comunidade Virtual do Museu Zoobotânico Augusto Ruschi e os resultados obtidos com a experimentação realizada para validar nossa tese.

\section{As Comunidades Virtuais de Aprendizagem Potencializando as Ações Educativas dos Museus}

Educar, no museu, não significa apenas mostrar ao público um grande rol de informações sobre peças do acervo e experimentos em exposição. Implica, sim, oportunizar vivências sensibilizadoras por meio de sua ação educativa; posteriormente, se o freqüentador julgar necessário, oferecer-lhe todas as 
informações disponíveis para sanar suas dúvidas, instigando sua curiosidade.

O museu é um espaço privilegiado, onde é possível concretizar ações educativas interdisciplinares envolvendo diferentes áreas e, ao mesmo tempo, produzir conhecimento a partir de temas e problemas que são potencializados no desenvolvimento das ações de pesquisa, preservação e comunicação.

É importante que cada museu procure maximizar a função educativa de seus acervos e atividades. Entre as propostas para o trabalho educativo em museus, Silva (2003) sugere o uso de novas tecnologias nas técnicas de estudo das exposições, permitindo novas formas de interação com os experimentos. Os museus interativos são ambientes ricos, atraentes e motivadores, que tanto envolvem o visitante nos processos da investigação científica como facilitam o acesso ao conhecimento científico. Conforme ressalta Moraes (2002), os museus interativos são excelentes ambientes para encaminhar aprendizagens significativas, as quais têm como elementos desencadeadores as interações propiciadas aos visitantes pelos experimentos. A experimentação dinâmica e interativa constitui-se num forte estímulo à compreensão e provoca a participação ativa dos visitantes.

Neste trabalho, partimos do pressuposto de que a informática, com suas ferramentas e tecnologias, é um excelente recurso para promover a interatividade nos museus de ciências. Logo, interagir é a palavra-chave que desencadeia o embasamento educacional dos museus modernos e que possibilita a construção de ambientes computacionais interativos, os quais facilitam a conexão entre o já conhecido pelo visitante e o novo. Para potencializar este processo, fazemos uso das Comunidades Virtuais (CV), as quais estão emergindo como um meio pelo qual as pessoas podem participar de grupos sociais mediados por computadores.

Uma CV de aprendizagem é aquela voltada a promover um ambiente que favorece a construção de conhecimento, cujos membros estão relacionados com objetivos em comum de aprendizagem. Essas comunidades podem promover a aprendizagem seguindo uma estrutura formal ou informal. Quando mencionamos a forma formal, estamos considerando que a comunidade irá formar-se com base numa estrutura física real, onde encontramos a figura do professor como facilitador e do aluno como sujeito ativo na construção de seu conhecimento.

Entretanto, este trabalho detém-se nas características obtidas por meio das comunidades de aprendizagem informais. Essas comunidades, para sua formação, contam com os interesses pessoais dos membros, de modo a definir uma rede de relacionamento auto-organizada, proporcionada pela comunicação interativa. Seus membros possuem objetivos comuns que os levem à aprendizagem contínua e permanente.

Para a definição do termo "informal" baseamo-nos na abordagem de Castells (apud SCHLEMMER, 2001), que trata do modo informacional de desenvolvimento presente nas CVs, o qual contribuirá para o surgimento de uma nova economia do conhecimento. Seguimos as idéias de Souza (2000), ao especificar que, mesmo em "....interações exclusivamente 'sociais' em comunidades virtuais, ocorre uma espécie de aprendizado contínuo e de grande valia, que atinge os participantes de forma heterogênea."

A "espécie de aprendizado" ressaltada pelo autor é aqui estabelecida como uma 
aprendizagem construtivista autodirigida, baseada na colaboração e na auto-organização, contando, para isso, com a participação ativa de todos os participantes. Segundo Pallof e Pratt (2002, p.39), a aprendizagem autodirigida habilita os membros de uma comunidade a seguirem interações onde quer que elas os levem, não sendo dependentes da figura do professor. Jonassen et al (PALLOF; PRATT, 2002) discutem o resultado dessa aprendizagem e observam que

(...) a facilidade proporcionada pelos ambientes de aprendizagem que estimulam a construção de sentido pessoal, bem como a construção social do conhecimento e do significado por meio de interações com outras comunidades de alunos, é preferível às intervenções do professor, que controlam a seqüência e o conteúdo da instrução.

O processo de aprendizagem autodirigida está centrado nos membros da comunidade que decidem o ritmo e a direção de todo o processo. Não é apenas o ambiente como um todo, mas a participação dos membros que sustenta e suporta muitas interações para que a aprendizagem ocorra. É durante esses processos de interação que os participantes ativos constroem e expressam competências.

Nesses ambientes, a comunicação assume um papel-chave, sendo essencial para que as interações sociais se estabeleçam de forma a conduzir os participantes à (re)construção de conhecimento por meio da colaboração, cooperação e interação. As interações sociais podem ser promovidas por meio de diferentes linguagens de comunicação, como, por exemplo: escrita síncrona (na forma de chat), escrita assíncrona (na forma de fórum) e leitura (das produções e objetos de aprendizagem - OAs). Com isso, é possível promover a comunicação interpessoal, ampliando as estratégias comunicativas e possibilitando que o visitante do museu influencie ainda mais a mensagem expositiva.

Nesse sentido, por meio de um entendimento do aprender baseado na interação, na comunicação e na linguagem, percebemos os museus interativos como espaços discursivos em que os visitantes mergulham e, assim, modificam suas estruturas. Diante disso, mostramos que as $\mathrm{CV}$ de aprendizagem, com as diferentes formas de comunicação que proporcionam, podem incentivar a aprendizagem informal dos museus. Isso ocorre pelo estímulo à produção individual e coletiva de OAs pelos visitantes do museu, pelo acesso a repositórios, onde esses OAs podem ser armazenados, recuperados e compartilhados por todos os visitantes, e por ferramentas comunicacionais que favorecem as trocas e diálogos entre os participantes. Para embassar essa afirmação, construímos o ambiente CV-Muzar com essas características e o avaliamos por meio de uma experimentação com um público-alvo diversificado no Museu Zoobotânico Augusto Ruschi (Muzar) da Universidade de Passo Fundo, conforme apresentaremos nas próximas seções.

\section{A Comunidade Virtual do Muzar (CV-Muzar)}

Como estamos visualizando um entendimento do aprender baseado na comunicação e na interação, pressupomos que conceitos como informação, comunicação e interação são essenciais para o processo de aprender no contexto informal dos museus. Acreditamos que a interação é parte integrante do processo de aprendizagem proporcionado por comunidades virtuais.

A Comunidade Virtual do Muzar (CVMuzar) (DE MARCHI, 2005) é composta por 
dois módulos principais (Figura 1): 1) o sistema de gerência de repositório de recursos didáticos: onde estão disponibilizados todos os OAs disponíveis. Este sistema foi implementado no Sistema de Gerência de Repositórios de OAs (GROA) (MIRANDA, 2004) e seguindo as extensões também propostas pelo $M$ LOM (Museu - Learning Object Metadata); 2) o ambiente de apoio à aprendizagem: serve para organizar as atividades didáticas, oferecendo aos visitantes on-line acesso a um conjunto de ferramentas de comunicação e a possibilidade de disponibilizarem suas próprias produções.

De acordo com a Figura 1, o visitante, por meio da interface do ambiente de comunidade virtual, pode interagir com os recursos do ambiente de aprendizagem e consultar os objetos de aprendizagem (OAs) do museu, pelo M-LOM. A consulta aos OAs considera as informações semânticas dos mesmos e permite sua fácil recuperação, considerando os objetivos educacionais do público em geral.

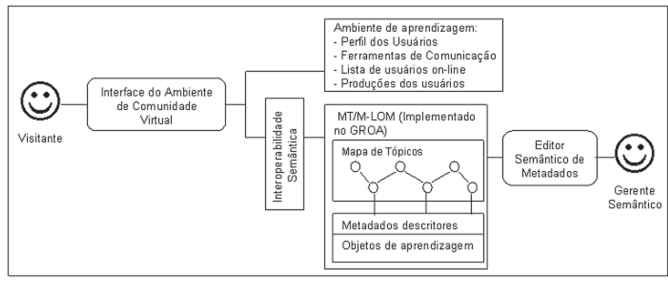

Figura 1 - Estrutura geral da CV-Muzar

Para permitir a recuperação semântica, os OAs são formados pelo recurso e o metadado descritor que segue as especificações M-LOM. Estes descritores são definidos pelo gerente semântico, o qual é representado pelo funcionário do museu conhecedor das coleções e artefatos. O M-LOM, definido para armazenar informações semânticas de objetos de aprendizagem dos museus, especifica um esquema de dados conceitual que define a estrutura do metadado para o objeto de aprendizagem. O M-LOM descreve um metamodelo para estender o LOM para uso em museus. Este modelo propõe: a definição de novos elementos de dados requeridos pela natureza da aplicação, a definição de vocabulários controlados para os elementos adicionais, e a definição de vocabulários adicionais aos elementos de dados LOM quando for conveniente à aplicação em museus.

Entre as extensões especificadas pelo M-LOM estão: 1) vocabulários adicionais foram propostos para refinar o elemento 5.6 Contexto da categoria educacional (Educational); 2) novos elementos foram propostos para as categorias: Geral (General): 1.9 Descrição Física; Técnica (Technical): 4.8 Download, com vocabulário controlado; e Direitos (Rights): 6.4 Proprietário.

A interoperabilidade é atingida com o uso da linguagem XML (Extensible Markup Language), na qual é possível exportar e importar os OAs no formato XML.

Adicionalmente, além da busca através das especificações do M-LOM, o ambiente proporciona uma busca hierárquica por meio do mapa de tópicos, que é definido pelo gerente semântico juntamente com os responsáveis pelas coleções do museu. Tal busca assemelha-se a uma varredura numa árvore onde os nodos folhas estão diretamente conectados aos elementos de dados do MLOM. Os mapas de tópicos podem auxiliar o gerente semântico a entrar com os dados numa forma semântica válida e também auxiliam o visitante a recuperar as informações (OAs), as produções dos usuários e os fóruns de discussão criados.

A junção entre o mapa de tópicos e o 
metadado descritor proporciona ao visitante duas formas distintas de buscar o recurso, a produção ou o fórum desejado nas bases do museu, facilitando sua pesquisa, tornando-a mais eficiente, precisa e rápida. Além disso, favorece diferentes perfis de visitantes: os que preferem uma busca por palavras-chave e os que aderem à navegação hierárquica (indexada) para encontrar a informação desejada.

Por sua vez, para a construção dos elementos básicos do ambiente de aprendizagem partimos do pressuposto de que a essência de um museu é a aprendizagem informal. Nosso objetivo é que o ambiente favoreça a aprendizagem ao longo da vida, de uma forma casual e espontânea, sem a existência de uma estrutura rígida e curricular. Dessa forma, estaremos oferecendo um espaço de encontros e convivências, promovendo discussões intelectuais, troca de conhecimentos, compartiIhamento de idéias entre pessoas com objetivos semelhantes, dirigidos apenas por seus interesses e necessidades.

Além de propiciar a pesquisa pela consulta ao repositório de OAs, o visitante tem a sua disposição um conjunto de ferramentas de comunicação, troca de informações, upload de produções. As ferramentas de comunicação fornecem as facilidades que permitem a troca e o envio de informações para possibilitar o trabalho cooperativo entre os visitantes. No caso, possibilitam a interação entre o sujeito-computador e sujeito-sujeito, incluindo mecanismos de discussão textual assíncrono no estilo de fórum (fórum), de bate-papo síncrono textual (chat) e lista de discussão por meio de correio eletrônico. Com as ferramentas de comunicação, favorecemos o estímulo à colaboração, ao diálogo e ao trabalho em grupo.

Na CV-Muzar, o visitante é estimulado a contribuir por meio de produções pessoais, as quais são entendidas como um movimento de reconstrução que envolve a reflexão, questionamentos, busca por novos conhecimentos, argumentação e explicitação de diferentes opiniões. Essas produções são incorporadas ao acervo do museu, tornando-se mais uma fonte de consulta. Na verdade, as produções são OAs construídos pelos visitantes. As produções podem ser documentos, multimídias, etc., tudo que for relevante para a aplicação e que o visitante considere importante para os demais participantes.

Uma característica importante do ambiente é que qualquer usuário pode efetuar anotações na produção de outro usuário. Essa ferramenta tem como objetivo fazer com que as contribuições dos visitantes sejam consideradas para o crescimento do trabalho intelectual. Desse modo, favorece-se a cooperação para a construção de produções pessoais. As anotações também podem ser utilizadas para a construção de uma produção coletiva, na qual todos contribuem. Com a ferramenta de produção, todo o participante da comunidade é considerado um autor e sua contribuição auxilia na construção do acervo de OAs do ambiente. Além disso, da mesma forma que o visitante pode contribuir para o aperfeiçoamento ou construção de uma produção do usuário, também pode realizar anotações a respeito dos recursos de aprendizagem do museu; influenciando a mensagem expositiva e contribuindo na construção da estratégia comunicativa do museu.

\section{A Experimentação realizada na CV-Muzar}

De modo a avaliar o incentivo à participação do visitante nas atividades de aprendizagem informal com relação à efetividade da 
sua produção, realizamos uma experimentação da CV-Muzar com um grupo de pessoas convidadas. A experimentação buscou mostrar que esses ambientes de aprendizagem, com as diferentes formas de comunicação que proporcionam, podem incentivar a aprendizagem informal dos museus. $O$ incentivo se dá pelo estímulo à produção individual e coletiva de OAs pelos visitantes do museu, pelo acesso a repositórios onde esses OAs podem ser armazenados, recuperados e compartiIhados e por ferramentas que apóiem o diálogo entre os participantes.

Com essa avaliação, foi possível identificar como e quanto o ambiente ajuda/desafia para um maior envolvimento do visitante na aprendizagem, criando oportunidades para melhorar o aprendizado não sistemático. A origem dessa análise vem da vivência nos museus, de uma compreensão intuitiva do que observamos e experimentamos a respeito da aprendizagem neste espaço.

Todos os usuários que participaram da experimentação responderam a dois questionários: o de expectativas e o de satisfação. Para a análise dos dados, estabelecemos o período de dois meses para a participação do grupo, durante o qual também foi monitorada a participação de cada usuário a fim de verificar o entrosamento entre si e com os recursos disponíveis. Com este monitoramento foi possível analisar as produções individuais e as atividades cooperativas que foram surgindo no decorrer do período e que serviram para sustentar ainda mais a idéia da comunidade como meio para promover a interação interpessoal. A seguir, apresentaremos os dados obtidos com os dois questionários aplicados durante a experimentação.

\subsection{Alguns resultados da análise dos questionários}

O questionário de expectativas foi respondido antes do primeiro contato dos participantes com a CV-Muzar. Ao todo foram 27 respondentes até o dia 3 de setembro de 2005, dos quais $67 \%$ eram mulheres e $48 \%$ possuíam entre 17 a 26 anos. Do total de respondentes, $37 \%$ já haviam utilizado alguma comunidade virtual para fins diversos, sendo este o entretenimento o mais procurado; $81 \%$ tinham ou tiveram alguma atividade relacionada com museus, e $85 \%$ mencionaram a internet como fonte para busca de referências em suas pesquisas. Esse questionário foi organizado em quatro categorias distintas: aspectos relacionados ao que o participante espera aprender de novo no ambiente; expectativas com relação às funções e recursos de interação disponíveis; expectativas com relação ao conteúdo a ser abordado; tipos de atividades que os museus devem oferecer para incentivar a aprendizagem.

Para ser possível interpretar o conteúdo coletado em cada categoria, realizamos uma análise qualitativa dos resultados obtidos. Para a realização desse processo seguimos as três fases apontadas por Gomes (2004): pré-análise, exploração do material e tratamento dos resultados obtidos e interpretação.

A primeira fase está relacionada com a organização do material a ser analisado, onde fizemos a leitura de todo o material, agrupando as respostas de modo a buscar padrões entre elas a fim de definir as categorias específicas. Na segunda fase aplicamos o que foi definido na fase anterior, ou seja, realizamos várias vezes a leitura do material buscando enquadrar as respostas nas categorias cria- 
das. A última fase pode ocorrer a partir do tratamento quantitativo e/ou podemos tentar desvendar o conteúdo subjacente ao que está sendo manifestado, procurando buscar tendências ou outras características dos aspectos que estamos analisando. No caso da análise do questionário de expectativas, nesta fase buscamos subsídios para auxiliar a elaboração do questionário de satisfação, respondido pelos participantes ao final da experimentação. O questionário de satisfação foi definido tendo como base os métodos dedutivo e indutivo. Para o método indutivo utilizamos a combinação de elementos obtidos com a análise do questionário de expectativas; já para o método dedutivo, fizemos uso das teorias que serviram de fundamento para a pesquisa.

O questionário de satisfação foi definido a partir de um conjunto de categorias definidas a priori, com base nas teorias que fundamentaram a pesquisa e sendo refinado pela construção de novas categorias e novas questões, tendo como referência os resultados obtidos com a análise do questionário de expectativas. $O$ instrumento foi preenchido pelos usuários no final do período de avaliação. Mais complexo que o de expectativas, continha perguntas organizadas em seis categorias e as genéricas. As categorias são: ambiente (responsável por avaliar desde a interação entre os participantes, até quanto o ambiente incentiva a produção individual e coletiva de produções); usabilidade (visa identificar problemas que possam comprometer a interação do usuário com a interface do ambiente); formas de pesquisa (busca identificar a opinião dos usuários sobre as diferentes formas de pesquisa que o ambiente disponibiliza, desde a pesquisa direta por objetos de aprendizagem até a busca hierárquica no mapa de tópicos); conteúdo/recursos (tem como objetivo analisar os conteúdos (OAs) do museu disponíveis no ambiente do ponto de vista de qualidade, confiabilidade, contextos de uso etc.); interação (visa identificar o nível de dificuldade do usuário em utilizar o ambiente como um todo); atendimento (avalia a equipe da CVMuzar em termos de atendimento às solicitações). Por sua vez, as perguntas genéricas buscam conduzir o usuário a emitir uma opinião geral sobre o ambiente, se atendeu ou não as suas expectativas, e apontar do que mais e menos gostara na CV-Muzar.

Para o preenchimento das seis categorias do questionário de satisfação, o usuário deveria observar a alternativa, de 1 a 5 , que melhor expressasse sua opinião, sendo 5 a de maior nota. Assim, cada questão possui cinco alternativas de respostas, às quais foram associadas notas. A análise das seis categorias parte de interpretações realizadas tomando como base, principalmente, dados quantitativos e procurando tecer relacionamentos com opiniões/sugestões apontadas de forma textual pelos participantes.

Considerando o objetivo desta avaliação, a categoria Ambiente é a mais importante, razão por que nos deteremos, neste artigo, apenas nos resultados obtidos com ela. Ela é composta por 16 questões (Figura 2) e a média final ficou em 4,5. As médias das questões individualmente podem ser visualizadas na Figura 3.

As questões d e $\mathrm{n}$ obtiveram notas $5 \mathrm{e}$ 4,9 , respectivamente. Este aspecto demonstra que os participantes desejam que suas contribuições sejam valorizadas, o que evidencia que o modelo de interação interpessoal aplicado neste trabalho reflete o desejo dos visitantes de incorporar suas mensagens ao acervo do museu. Além disso, demonstra 
a) Você se senbiu estimulado a contrīuir através de tocas realizadas entre as usuárias por meio de mensagens nas toruns?

b) Vacê se sentiu estimuladio a contribuir através de dílogos realizacios por mejo de mensagens nas salas de bato-papo? c) Você se sentiu estimulado a contribui por meio de produçóes textusis ou outras?

d) O que você achou do possibiliade das prodiucōes dos usuánios serem incorooradas ao aceno do Musel?

e) O que você achou da possibuidade de associar o acenvo do museu, as prodichóes dos usub́nos e os fóruns de discussäo em uma mesma estrutura de consuRa?

f) Você acha gut a CV-Muzar oferece diferentes inguagens (toxto, imagem, animaçäo, etc.) para expor o conteúdio abordado?

g) Você acha cue a CV-Muzar, por estar disponivel vitualmente, tana mais fácil para o usuánio contibuxi, seja por mejo de uma anotaçã ou prodiçä́?

h) Você sente cue suas contribuçöes säo mais vaionizadas através de um ambiente wintual como a CK-Muzar?

i) Você considera que a CV-Muzar auxiliará os museus a incentivarem a aprendizagem?

j) O quanto 0 ambiente the ajuwou na produçäo individual do materiais?

k) O cuanto o ambiente the awdow na producäo colebiva de materisis?

1) Você acha que o ambiente proporciona ferramentas a dequadas para os usuŕrios trocarem idéjas?

m) Você acha que o ambiente proporciona feramentas adequadas para os usuários compartihavem conhecimentas?

n) O que você acha da possibiidade de viswalizar as prodiçöes dos outras usuánios?

o) Vocé acha cue as outros usuánios, através das ferramentas disponiveis no ambiente, podem colaborar com as suas produçbes?

p) Você conseguiu aprender o que desejava como uso do ambiente?

Figura 2 - Questões da categoria Ambiente

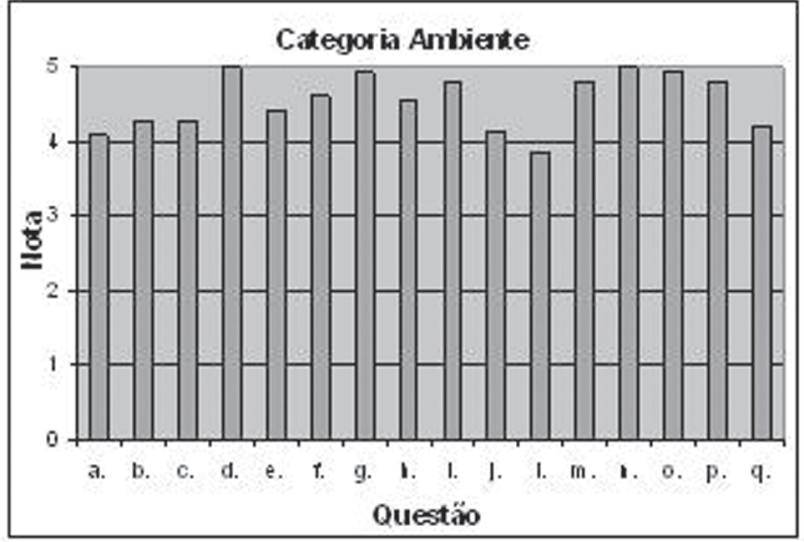

Figura 3 - Categoria Ambiente

que os participantes estão abertos à cooperação e à colaboração, no sentido de receber/ construir críticas, opiniões e sugestões, qualificando argumentos de modo a ampliar pontos de vista.

Adicionalmente, os participantes sentiram-se mais estimulados a contribuir por meio de produções e diálogos promovidos nas salas de bate-papo do que por mensagens trocadas nos fóruns. Na grande maioria, as produções consistiam em artigos relacionados ao conteúdo da comunidade, os quais foram ela- borados pelos participantes e disponibilizados na área das produções. Os participantes também acreditam que o fato de a CV-Muzar estar disponível virtualmente torna mais fácil para o usuário contribuir, seja por meio de anotações, seja por produções. Essa questão obteve média 4,9 e demonstra que o uso das tecnologias de informática para auxiliar a aprendizagem informal em museus é muito bem aceita e desejada, uma vez que possibilita o acesso independente de tempo e espaço. Além disso, os participantes consideram que suas contribuições são mais valorizadas por 
meio da CV-Muzar. Esses aspectos vêm a favor das expectativas dos usuários, dos quais $67 \%$ apontaram a disponibilização de materiais na internet e a construção de multimídias como tipos de atividades que os museus devem oferecer para incentivar a aprendizagem.

Um dos aspectos mais importantes para a experimentação era identificar se o ambiente incentiva a aprendizagem informal em museus, pelo envolvimento/participação do visitante nas atividades. Apesar de ser possível constatar essa afirmação pelas respostas anteriores, a questão foi colocada aos entrevistados de forma bem direta (questão i). Como resposta, obtivemos nota 4,8 , o que comprova nossa tese. Outro fator que confirma a constatação de que apenas $15 \%$ das produções foram desenvolvidas de forma coletiva é que os participantes atribuíram nota 3,9 à questão que procurou identificar o quanto o ambiente ajudou na produção coletiva de materiais (questão k). Argumentamos que a principal causa com relação a este aspecto foi o tempo não suficiente para que os visitantes encontrassem um conjunto considerável de produções já realizadas e disponibilizadas e se motivassem a estudar o material já produzido anteriormente por outros visitantes. Se a experimentação durasse mais tempo, talvez uma tarefa a que os participantes pudessem se dedicar fosse a busca no material já disponibilizado, tomando-o como ponto de partida para a criação de novas produções. Esse fato ocorreu porque os primeiros participantes não encontraram nenhuma produção já cadastrada anteriormente. A primeira produção a ser cadastrada foi efetivada durante o período de experimentação, mais precisamente no $15^{\circ}$ dia. Não atribuímos o baixo número de produções coletivas à falta de ferramentas para auxiliar a produção, visto que os participantes apontaram que o ambiente proporciona ferra- mentas adequadas para a troca de idéias entre os usuários (nota 4,8) e que cada um pode colaborar com as produções dos demais participantes por meio das ferramentas disponíveis (nota 4,8). Neste aspecto o ambiente também respondeu satisfatoriamente às expectativas dos usuários, dos quais $48 \%$ apontaram a necessidade de que possua ferramentas que possibilitem a comunicação, a interação e a troca de informações. No entanto, como trabalho futuro, pretendemos adicionar uma ferramenta de edição colaborativa, de forma a promover ainda mais o incentivo à produção em conjunto.

Diante do exposto, podemos citar vários indícios que nos levam a concluir que nosso objetivo foi alcançado:

1. a média de duas produções por participantes é considerada excelente, levando em conta o curto período para os participantes se familiarizarem com o ambiente e com os demais usuários e iniciarem suas produções;

2. o fato de os participantes aprovarem a possibilidade de visualizar as produções dos usuários permite que os visitantes aproveitem as produções realizadas por visitantes anteriores, as quais podem, inclusive, ser utilizadas fora do museu;

3. o alto grau de aprovação das ferramentas comunicacionais como um todo e, principalmente, o fato dos demais participantes poderem colaborar com as produções mostram que nosso entendimento do aprender em museus realmente possibilita perceber estes ambientes interativos como espaços discursivos em que os visitantes mergulham e por eles são modificados;

4. a nota máxima atribuída ao fato de o ambiente possibilitar que as produções dos 
usuários sejam incorporadas ao acervo do museu e a grande aceitação em permitir que os usuários contribuam por meio de anotações nos recursos evidenciam a facilidade de incorporar o feedback do visitante à mensagem.

\section{Considerações Finais}

Com a mudança no conceito dos museus, eles passaram a agregar a interatividade como forma de ampliar a função educativa, bem como de intensificar a comunicação na educação. Dessa forma, o museu une o social e o cultural de modo a aumentar seu papel educacional, oferecendo ao público diversas ações educativas. Com recursos extras de interatividade, os visitantes poderão contar com espaços de discussões virtuais independentes de tempo e espaço; de um local onde suas contribuições são engajadas ao acervo do museu e onde é permitida a participação do público em geral. Isso tudo sem estruturas predefinidas e sem o papel do professor e aluno, favorecendo uma aprendizagem informal não necessariamente intencional.

Esses aspectos são viáveis graças à junção da informática e das diferentes linguagens comunicacionais, as quais apresentam um papel fundamental para auxiliar na compreensão dos objetos em exposição e promover a interação social.

Com a análise dos dados oriundos da experimentação foi possível verificar vários indícios de que um ambiente, como o proposto aqui, realmente incentiva um maior envolvimento do visitante na aprendizagem informal, tais como: o número alto de produções indivi- duais construídas; o fato de os usuários acharem que suas contribuições são mais bem aproveitadas num ambiente virtual, podendo influenciar de forma mais direta na mensagem expositiva; a maior facilidade de promover trocas e diálogos, compartilhando conhecimentos com o uso de ferramentas comunicacionais que fazem uso da virtualização das linguagens; o desejo dos visitantes de contribuir, pelas de produções individuais e coletivas, com o acervo do museu; o grande número de usuários que vêem a informática como um tipo de atividade que os museus devem oferecer para incentivar a aprendizagem, e o alto interesse em criar um ciclo discursivo para dialogar sobre assuntos afins, de modo a permitir uma maior troca de experiências.

Para os museus, além de comunicadora, a informática é um canal de pesquisa que disponibiliza maior e melhor acesso aos recursos. Desse modo, devemos compreender o ambiente de comunidade virtual como um incentivador da dinâmica dos processos cognitivos, privilegiado para a aprendizagem como momento socialmente partilhado de construção do conhecimento.

A CV-Muzar pretende contribuir na desmistificação da visão tradicional de museu e promover a sensibilização e conscientização da sociedade na valorização das culturas tradicionais e na troca e disseminação de conhecimento. Com a realização desta pesquisa mostramos ser viável envolver o visitante num ciclo discursivo promovido por meio da comunicação, possibilitando que suas contribuições sejam incorporadas ao contexto sociocultural dos museus. 


\section{Agradecimentos}

Agradecemos ao Conselho Nacional de Desenvolvimento Científico e Tecnológico - CNPq e à Fundação de Amparo a Pesquisa do Rio Grande do Sul.

\section{Referências}

BLANCO, Ángela. La exposición, un medio de comunicación. Madrid: Alral, 1997.

DE MARCHI, Ana Carolina Bertoletti. Um ambiente de suporte a comunidades virtuais baseadas em repositórios de objetos de aprendizagem para apoio à aprendizagem informal em museus. Porto Alegre: UFRGS, 2005. 225p. Tese (Doutorado) - Programa de Pós-Graduação em Informática na Educação, Universidade Federal do Rio Grande do Sul, Porto Alegre, 2005.

GOMES, Romeu. A análise de dados em pesquisa qualitativa. In: MINAYO, Maria Cecília de Souza. (Org.) Pesquisa Social Teoria, método e criatividade. Rio de Janeiro: Vozes, 2004, p.67-80.

MIRANDA, Raquel. GROA - Um Sistema de Gerencia de Repositórios de Objetos de Aprendizagem. Porto Alegre: UFRGS, 2004. Dissertação (Mestrado) - Programa de Pós-Graduação em Ciência da Computação, Universidade Federal do Rio Grande do Sul, Porto Alegre, 2004.

MORAES, Roque. De descobertas a apropriações de discursos: aprendizagens em museus interativos. Porto Alegre: EDIPUCRS, 2002.

PALLOFF, Rena e PRATT, Keith. Construindo Comunidades de Aprendizagem no Ciberespaço: Estratégias eficientes para salas de aula on-line. Trad. Vinícius Figueira. Porto Alegre: Artmed, 2002.

SANTOS, Maria Cristina. Museu, Escola e Comunidade - Uma integração necessária. Salvador, BH: Bureau Gráfica e Editora, 1987.

SCHLEMMER, Eliane. Projetos de Aprendizagem baseados em problemas: uma metodologia interacionista/construtivista para formação de comunidades em ambientes virtuais de aprendizagem. Colabora - Revista Digital da CVA - RICESU, Curitiba, v.1, n.1, p. 4-11, 2001.

SILVA, Margarida Pantaleão. Ação Pedagógica: Uma questão a ser (re)pensada nos Museus de Arte. Porto Alegre: UFRGS, 2003. Dissertação (Mestrado) - Programa de Pós-Graduação em Educação, Universidade Federal do Rio Grande do Sul, Porto Alegre, 2003.

SOUZA, Renato Rocha. Aprendizagem Colaborativa em Comunidades Virtuais, Florianópolis: UFSC, 2000. Dissertação (Mestrado) - Programa de Pós-Graduação em Engenharia de Produção, Universidade Federal de Santa Catarina, Florianópolis, 2000. 
Ana Carolina Bertoletti de Marchi

ICEG - CCC - UPF / PGIE - UFRGS

Caixa Postal 611, CEP 99001-970, Passo Fundo, RS, Brasil

55-54-3316-8354

carolina@upf.br

Área de Atuação: Informática na Educação

Grupo de pesquisa: Informática na Educação/UPF

\section{Antônio Carlos da Rocha Costa}

EI-UCPel / PGIE - UFRGS

R. Félix da Cunha, 412 Pelotas, RS, Brasil

55-53- 3284-8227

rocha@atlas.ucpel.tche.br

Área de atuação: Inteligência Artificial

Grupo de Pesquisa: GPIA/UCPel - Grupo de Inteligência Artificial 